\title{
Traumatic Isolated Radial Head Dislocation in Children: A Case Report
}

\author{
Gamal Ayouba, Atchi Walla, Batarabadja Bakriga \\ Unity of Orthopedic in Regional Hospital Center of Kpalime, Kpalime, Togo \\ Email: gamal792003@yahoo.fr
}

How to cite this paper: Ayouba, G., Walla, A. and Bakriga, B. (2016) Traumatic Isolated Radial Head Dislocation in Children: A Case Report. Open Journal of Orthopedics, 6, 344-349.

http://dx.doi.org/10.4236/ojo.2016.611046

Received: October 22, 2016

Accepted: November 20, 2016

Published: November 23, 2016

Copyright $\odot 2016$ by authors and Scientific Research Publishing Inc. This work is licensed under the Creative Commons Attribution International License (CC BY 4.0). http://creativecommons.org/licenses/by/4.0/

\begin{abstract}
The isolated dislocation of the radial head is frequently described in the lesion of MONTEGGIA. However it can be a rare isolated pattern of injury in children. Only 81 cases were reported in the literature to our knowledge. The case we report concerns a 13 years old boy, examined 8 days after injury. Because of failure of manual reduction, we performed a surgical management with excellent results after a year of follow-up. We have discussed treatment option and the results obtained.
\end{abstract}

\section{Keywords \\ Radial Head, Dislocation, Children}

\section{Introduction}

Isolated dislocation of the radial head in children is frequently described as part of a congenital dislocation [1]. Isolated dislocation of the radial head in a traumatic context is exceptional [1] [2] [3] because it is described in Monteggia's lesion. To our knowledge until 2004, only 81 cases were reported in the literature since the first description by Duverney in 1751 [4] [5]. The mechanism is still controversed [3]. The diagnostic in acute case is based on clinical examination and must exclude Monteggia's lesion and congenital dislocation through the X-rays. Whether the management should be conservative or operative depends on the ease of reduction and of maintenance, as well as the delay management starts [6]. Good results have been reported for their early management, less than a week after trauma, by closed reduction and cast immobilisation [6] [7]. Management for the cases with excessively delay diagnostic, by three weeks and more, is controversial [6].

We reported another traumatic dislocation of the radial head in children treated surgically 8 days after trauma with excellent results. This case was particular because of 
delay diagnostic and failure of closed reduction. We have reviewed different aspects of this lesion according to literature and discussed optional treatment.

\section{Case Presentation}

We received in clinic a young boy of 13 years old, for the right elbow with that his sustained after falling from his bicycle8 days ago. He had failed down on the hand turned in internal rotation with his elbow extended. The examination of the elbow showed a relative lameness, a bony prominence facing the radial head without associated neurovascular disorder. The X-ray of the elbow showed a posterior and lateral displacement of radial head. There was any associated fracture or bending of the ulna (Figure 1). The diagnostic retained was posterior and lateral radial head dislocation 8 days after trauma.

At this stage it decided to perform a close reduction under fluoroscopic guidance. The procedure of reduction was an axial traction associated with a forced and full supination of the forearm and direct pressure on the radial head. The reduction was failure because of an irreductibility, then we performed an open reduction. This was done by posterolateral approach of elbow. After opening, we founded a jailed capsule which was extricated and a rip of annular ligament. The proximal radio-ulnar joints have been fixed by K-wire and the annular ligament was repaired. After closure, the elbow was then immobilized by a brachio-volar plaster for 21 days with the forearm in full supination. The K-wire was removed after 21 days. The patient was under gentle physiotherapy for 3 weeks.

Six weeks after surgery, the patient had $115^{\circ}$ of flexion and a lack of $5^{\circ}$ of extension. The pronosupination was $0^{\circ}-25^{\circ}$. The X-ray showed an almost restored Storen's line on AP and lateral view (Figure 2). There was no sign of callus on ulna.

After a year of follow up, clinical examination (Figure 3 ) was very satisfactory. The elbow flexion was $135^{\circ}$, the extension was complete, the pronation and supination was total. The humuro-radial axis was normal on AP and lateral view of radiography of

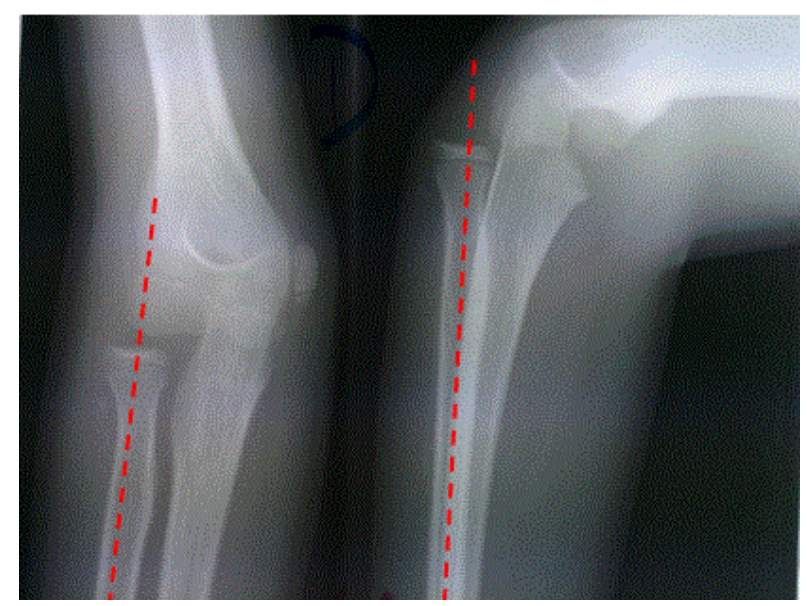

Figure 1. Lateral and posterior displacement of radial head on X-ray of elbow. The axis of radius does not cross capitulum. 




Figure 2. X-ray 6 weeks after surgery. It remained little displacement on lateral view. The ulna was not seen. Any signs of callus on ulna.

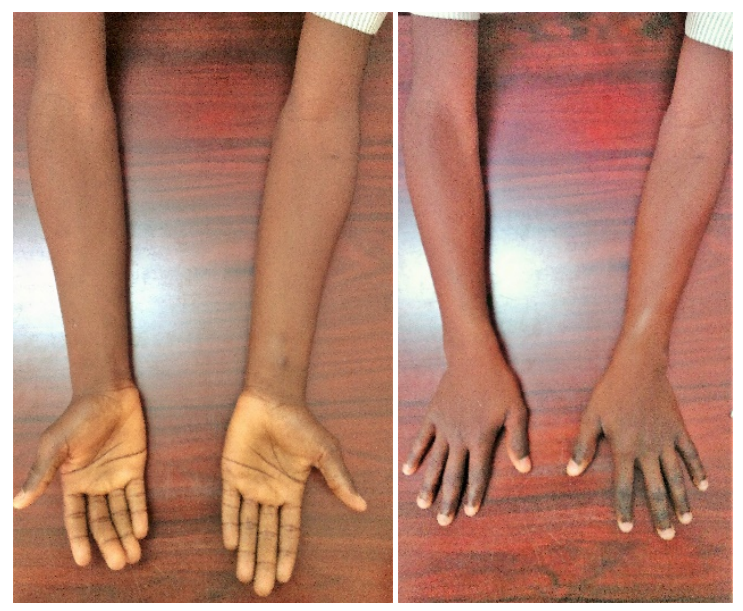

Figure 3. Supination and pronation aspect after 1 year follow-up.

elbow (Figure 4).

\section{Discussion}

The occurrence of an isolated traumatic dislocation of the radial head is controversial, because it is generally described in a Monteggia's lesion. Hume [2] reported that the flexibility of children's bone allows the ulna to bend. Vesely D. [3] meanwhile suggested the presence of an occult fracture of the ulna that a careful examination of the forarm $\mathrm{X}$-ray should detected. In our case, both bending and fracture of ulna were not seen on $\mathrm{X}$-ray.

A complete dislocation of the radial head can't occur without complete rupture of the annular ligament [6] [7] which is the main factor in the stability of the proximal radioulnar 


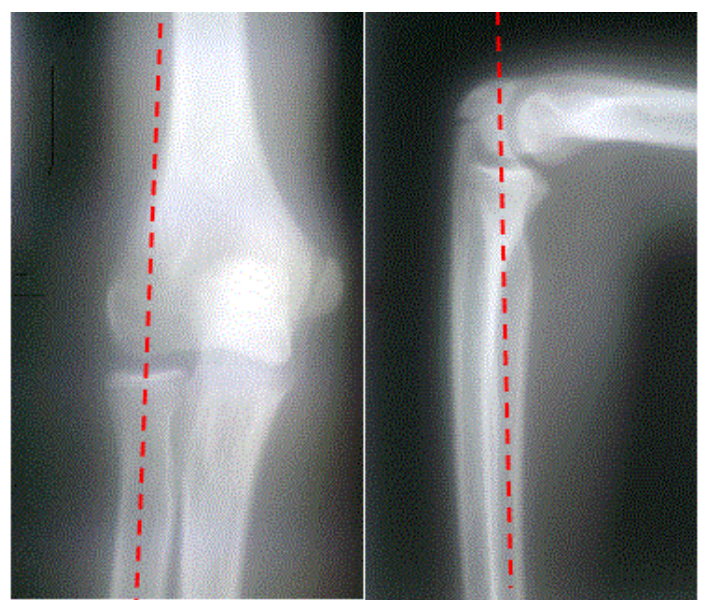

Figure 4. X-ray views after 1 year follow-up. The Storen's line is restaured.

joint. The other ligaments structures like interosseous membrane, the square ligament and the oblique cord have a secondary role in the stability of the elbow [7]. Three types of isolated luxation are described: posterior, anterior and lateral. Anterior dislocation is the most common form [6] [7], in contrary our patient had posterior and lateral form which is uncommon.

The mechanism is not well known: two opposing theories are described. One is a forced hyper pronation forearm on elbow in extension with or without varus has been described [3] [8]. The other is hyper forced elbow extension on full supination of the forearm with or without tear of the biceps [9] [10]. The mechanism precisely described in our case, similarly reported by Damak [4], was the application of the full weight of his body (falling forward off his bike) on elbow in extension with forced pronation of the forearm with the hand in internal rotation (the position of the hand holding the handle).

For the diagnosis, in a recent trauma the physical examination searched for a painful limitation of motion of the elbow. Passive movements are sometimes possible in flexion and extension but are limited and painful in pronation and supination especially [6]. The persistence of functional discomfort with or without joint limitation and/or neurological signs bring the patient to again consultation [4] [5]. In our case, the diagnosis was done a week after the trauma. Despite this delay of diagnostic our case was considered like an acute case. However dislocation can go unnoticed and persist for more than three months, it is called chronic dislocation [5]. The antero-posterior and lateral views of radiography allow to establish the diagnosis and shows the deformity of Storen's line [4] [5] (Figure 1). The antero-posterior view the X-ray shows an external or internal displacement of the radial head according to the lateral condyl of humerus. The lateral view of X-ray shows anterior or posterior displacement whose importance is evaluated according to the distance of the radial head from to the tip of the coronoid processes. The forearm X-ray helps to exclude Monteggia's lesion, and an X-ray of the opposite elbow to exclude a congenital dislocation [3]. In our case, there were any signs of 
ulna fracture or callus (Figure 2 and Figure 4).

The management of recent radial head dislocation in children is non operative. It is close reduction under general anesthesia with an immobilisation by plaster where the elbow is in $90^{\circ}$ of flexion and forearm forced supination for 3 to 6 weeks [3] [6] [8]. The failure of the reduction may be due to interposition of the capsule as we saw it in our case and biceps [11] [12]. In our case a failure of reduction was due to a jailed capsule. The repair of the capsule in case of open reduction is not systematic [11]. We performed a repair of the annular ligament and fixation by K-wire for the proximal radio ulna joint. But this K-wires fixation seems not to be essential [5] after closed reduction.

The functional outcome is generally satisfactory for a recent injury after 1 to 3 years of follow-up [4] [10]. In our patient, the functional outcome after a year of follow-up was very satisfying.

In the event of a neglected dislocation of more than three weeks, the open reduction is best way of treatment and it uses various techniques based on the radial osteotomy and/or ulnar. The results are mixed when comparing the loss of mobility due to surgery and instability before surgery [6] [13]. That is why conservative procedure is recommended by some authors [4] [14] in case of a neglected dislocation.

\section{Conclusion}

Traumatic radial head dislocation is exceptional in children. Radiography of all forearms and the second elbow confirms the diagnosis and should help to exclude a Monteggia injury, and congenital dislocation. Surgical treatment is indicated in case of failure of conservative treatment. The prognosis is usually good in acute cases treated conservatively or surgically and it is controversial in chronics dislocations treated by osteotomy.

\section{References}

[1] Gunn, D.R. and Pillay, V.K. (1964) Congenital Posterior of the Head of the Radius. Clinical Orthopaedics and Related Research, 34, 108-113.

[2] Hume, A. (1957) Anterior Dislocation of the Radial Head in Children Associated with Undisplaced Fracture of the Ulna. The Journal of Bone \& Joint Surgery(British), 39, 508-512.

[3] Vesely, D. (1967) Isolated Traumatic Dislocation of the Radial Head in Children. Clinical Orthopaedics and Related Research, 50, 31-36.

[4] Damak, B., Triki, H., Karray, N., Rebaï, M. and Keskes, H. (1998) La luxation traumatique antérieure isolée de la tête radiale. A propos de 2 cas. Acta Orthopaedica Belgica, 64, 413417.

[5] Boumpoutou, R., Guérin, B., Boroco, A., Mouret, G. and Choulot, J.-J. (2004) Luxation post-traumatique isolée de la tête radiale chez un enfant. JEUR, 17, 79-82. https:/doi.org/10.1016/s0993-9857(04)96019-0

[6] Hudson, D. and De Beer, J. (1957) Isolated Traumatic Dislocation of the Radial Head in Children. The Journal of Bone \& Joint Surgery, 39, 378-381.

[7] Wiley, J.J., Peginton, J. and Horwich, J.P. (1974) Traumatic Dislocation of the Radius at the Elbow. The Journal of Bone \& Joint Surgery (British), 56, 501-507.

[8] Evans, E.M. (1949) Pronation Injuries of the Forearm with Special Reference to the Ante- 
rior Monteggia Fracture. The Journal of Bone \& Joint Surgery(British), 31, 578-588.

[9] Smith, F.M. (1972) Surgery of the Elbow. 2nd Edition, WB Saunders, Philadelphia.

[10] Hamilton, W. and Parkes, J. (1973) Isolated Dislocation of the Radial Head without Fracture of the Ulna. Clinical Orthopaedics and Related Research, 97, 94-96.

[11] Neviaser, R. and LeFevre, G. (1971) Irreductible Isolated Dislocation of the Radial Head: A Case Report. Clinical Orthopaedics and Related Research, 80, 72-74.

[12] Veenstra, K. and Van der Eyken, J. (1993) Irreductible Antero-Medial Dislocation of the Radius. A Case Report Tendon Interposition. Acta Orthopaedica Scandinavica, 64, 224-225. https:/doi.org/10.3109/17453679308994576

[13] Lloyd, R.G. and Buckmill, T. (1977) Anterior Dislocation of the Radial Head in Children: Aetiology, Natural History and Management. The Journal of Bone \& Joint Surgery (British), 59, 402-407.

[14] Stelling, F. and Cote, R. (1956) Traumatic Dislocation of Head of the Radius in Children. JAMA, 160, 732-736. https:/doi.org/10.1001/jama.1956.02960440004002

Submit or recommend next manuscript to SCIRP and we will provide best service for you:

Accepting pre-submission inquiries through Email, Facebook, LinkedIn, Twitter, etc.

A wide selection of journals (inclusive of 9 subjects, more than 200 journals)

Providing 24-hour high-quality service

User-friendly online submission system

Fair and swift peer-review system

Efficient typesetting and proofreading procedure

Display of the result of downloads and visits, as well as the number of cited articles

Maximum dissemination of your research work

Submit your manuscript at: http://papersubmission.scirp.org/

Or contact ojo@scirp.org 